\title{
Enzimas digestivas exógenas na alimentação de juvenis de tambaqui
}

\author{
Érica da Silva Santiago Nunes( ${ }^{(1)}$, Bruno Adan Sagratzki Cavero(2), Manoel Pereira-Filho(1) e Rodrigo Roubach ${ }^{(1)}$
}

(1)Instituto Nacional de Pesquisas da Amazônia, Coordenação de Pesquisas em Aquacultura, Av. André Araújo, 2936, no Caixa Postal 478, Petrópolis, CEP 69069-001 Manaus, AM. E-mail: ericassn@inpa.gov.br, pmanoel@inpa.gov.br, roubach@inpa.gov.br (2)Universidade Federal do Amazonas, Fac. de Ciências Agrárias, Dep. de Ciências Pesqueiras, Av. Gal. Rodrigo O.J. Ramos, no 3000, Coroado, CEP $69077-000$ Manaus, AM. E-mail: basc@ufam.edu.br

\begin{abstract}
Resumo - O objetivo deste trabalho foi avaliar o efeito da adição na ração das enzimas digestivas exógenas amilase, lipase e protease sobre o desempenho de tambaqui, em três experimentos independentes. Em cada experimento foi avaliado o efeito da inclusão de uma enzima na ração em diferentes porcentagens: 0,0, 0,05, 0,1 e $0,2 \%$, cada uma com quatro repetições, com 28 dias de duração. Foram realizadas biometrias do peso inicial, para homogeneização da amostra, e do peso final a fim de verificar o efeito dos tratamentos sobre o desempenho dos peixes. Em cada unidade experimental foram estocados dez peixes, alimentados duas vezes ao dia ( 8 e $14 \mathrm{~h}$ ) até a saciedade aparente, com ração comercial extrusada com $28 \%$ de proteína bruta, triturada, adicionada de enzima e depois peletizada. Ao final do experimento, o ganho de peso, a conversão alimentar aparente e o crescimento específico dos peixes, apresentaram diferenças significativas entre os tratamentos. As enzimas exógenas amilase a $0,05 \%$ e lipase a $0,2 \%$ na ração influenciaram o desempenho zootécnico de juvenis de tambaqui. A adição de protease exógena não apresenta a mesma influência.
\end{abstract}

Termos para indexação: Colossoma macropomum, piscicultura, nutrição de peixes, amilase, lipase, protease.

\section{Exogenous digestive enzymes in tambaqui juvenile feeding}

\begin{abstract}
The objective of this work was to evaluate feed addition of exogenous digestive enzymes amylase, lipase, and protease on the tambaqui performance in three independent experiments. In each experiment, the effect of different percentages of enzyme inclusion in the feed was evaluated: $0.0,0.05,0.1$ and $0.2 \%$, each with four repetitions, in a 28 days duration. Initial biometrics for the initial weight were performed for sample homogenization, and for the final weight, to verify treatments effect on fish performance. Each experimental unit was stocked with ten fish, and fed on up to apparent satiety twice a day (8 and 14h), on a commercial extruded feed containing $28 \%$ crude protein, grounded, added enzymes levels and then pelleted. At the end of the experiment weight gain, apparent feed conversion, and specific growth rate presented significant differences between treatments. Exogenous enzymes amylase at $0.05 \%$ and lipase at $0.2 \%$ in diets influenced juvenile tambaqui zootechnical performance. The addition of the exogenous protease did not present the same influence.
\end{abstract}

Index terms: Colossoma macropomum, fish culture, fish nutrition, amylase, lipase, protease.

\section{Introdução}

O tambaqui, Colossoma macropomum, é uma espécie pertencente à família Serrasalmidae e à subfamília Serrasalminae. Peixe de piracema nativo das bacias dos rios Solimões, Amazonas e Orinoco é amplamente distribuído na parte tropical da América do Sul e na Amazônia Central, e muito apreciado por seu sabor, sendo importante fonte de proteína animal (Araújo-Lima \& Goulding, 1997). O tambaqui é onívoro com tendência a herbívoro, filtrador e frugívoro. Tem grande capacidade de digerir proteína animal e vegetal e de fácil adaptação à alimentação fornecida.
É a primeira espécie sobre a qual se conhece o suficiente de modo a manejar os estoques naturais e promover sua criação em cativeiro (Araújo-Lima \& Goulding, 1997), despertando, assim, a expectativa de melhorar seus índices zootécnicos a partir da adoção de novas tecnologias.

Há poucas décadas, a forma mais comum de piscicultura dessa espécie era o cultivo extensivo, sem a adição de alimento suplementar, em que apenas a produtividade natural sustentava uma baixa densidade de indivíduos, o que resultava numa baixa eficiência de produção. Estudos recentes têm demonstrado que a dieta influencia o comportamento, a integridade estrutural, 
saúde, funções fisiológicas, a reprodução e o crescimento dos peixes (Takahashi, 2003).

Segundo Pereira Filho (1995), em piscicultura intensiva, os gastos com alimentação podem representar cerca de 50 a $80 \%$ dos custos de produção. Portanto, para que se otimize a relação custo/benefício, é necessário considerar os aspectos qualitativos e quantitativos da alimentação.

Devido ao custo cada vez maior das matérias-primas tradicionais utilizadas nas formulações de rações, o interesse no uso de enzimas exógenas em dietas tem aumentado e sua utilização é, portanto, uma alternativa para aumentar a digestibilidade dos alimentos e o desempenho dos animais (Cavero, 2004).

As enzimas também são consideradas importantes na redução da contaminação ambiental, auxiliando a digestibilidade dos nutrientes, o que reduz a eliminação de excretas na água (Mora-Jaímes et al., 2002).

O objetivo deste trabalho foi avaliar o efeito da adição das enzimas digestivas exógenas amilase, lipase e protease na ração sobre o desempenho de juvenis de tambaqui.

\section{Material e Métodos}

Os trabalhos foram realizados na Coordenação de Pesquisas em Aquacultura (CPAQ), do Instituto Nacional de Pesquisa da Amazônia (Inpa), de 22 de outubro de 2003 a 24 de maio de 2004, em três experimentos independentes. Cada experimento avaliou o efeito de uma das seguintes enzimas na ração: amilase - obtida a partir do fungo Aspergillus oryzae, protocolo 02-D394; lípase - obtida a partir do fungo Aspergillus niger, protocolo 02-D394; e protease - obtida a partir do fungo Aspergillus oryzae, protocolo 02-D394.

Cada experimento, com duração de 28 dias, foi conduzido em delineamento inteiramente casualizado com quatro tratamentos (representados pelos níveis de inclusão da enzima 0,0, 0,05, 0,1 e 0,2\%), cada um com quatro repetições, totalizando 16 unidades experimentais por enzima ensaiada. As unidades experimentais foram constituídas por tanques de PVC com $250 \mathrm{~L}$ cada, com uma entrada e uma saída de água, com renovação constante (fluxo de 4,5 $\mathrm{L} \mathrm{h}^{-1}$ ) e independentes entre si.

Para verificar a homogeneidade dos tratamentos, no início dos experimentos, todos os peixes foram pesados. Em todos os experimentos, os peixes foram alimentados até a saciedade aparente, duas vezes ao dia (8 e 14h), com ração comercial extrusada, com 28\% de proteína bruta e suplementada com aditivo enzimático nas doses definidas para cada tratamento. A ração foi triturada e nela misturou-se homogeneamente a enzima nos níveis dos tratamentos. Depois deste processo, a ração foi peletizada (com péletes de aproximadamente $0,25 \mathrm{~cm}$ ) e secada a $33^{\circ} \mathrm{C}$ durante 24 horas. A qualidade da água dos tanques foi monitorada diariamente, por medição da amônia total $\left(\mathrm{NH}_{3}+\mathrm{NH}_{4}{ }^{+}\right)\left(\mathrm{mg} \mathrm{L}^{-1}\right)$, condutividade elétrica $\left(\mu \mathrm{cm}^{-1}\right)$, temperatura $\left({ }^{\circ} \mathrm{C}\right)$, $\mathrm{pH}$ e oxigênio dissolvido $\left(\mathrm{mg} \mathrm{L}^{-1}\right)$.

Ao final dos experimentos, os peixes foram submetidos a biometrias de peso (em gramas) para verificar o efeito dos tratamentos sobre o seu desempenho.

Em todos os experimentos, foram analisados os seguintes parâmetros de desempenho: ganho de peso (GP) = peso médio final - peso médio inicial; consumo médio de ração individual (CMDI) = quantidade de ração fornecida por dia (g)/número de peixes; consumo individual médio de ração ao final do experimento $(\mathrm{CIMFi})=\Sigma \mathrm{CMDi}$; conversão alimentar aparente $(\mathrm{CAA})=\mathrm{CIMFi} /($ peso médio final - peso médio inicial); crescimento específico em peso dos peixes $(C E P)=100($ ln peso médio final - ln peso médio inicial)/tempo; taxa de sobrevivência dos peixes (TS) = 100(número final de peixes/número inicial de peixes).

Os resultados dos índices zootécnicos e da qualidade da água dos experimentos foram analisados mediante a análise de variância (ANOVA). Quando os tratamentos apresentaram efeitos significativos, as médias foram comparadas pelo teste de Tukey (Mendes, 1999). Ambas as análises foram realizadas a 5\% de probabilidade.

\section{Resultados e Discussão}

Em todos os experimentos, os parâmetros físico-químicos da água não apresentaram variações que pudessem interferir no desempenho dos peixes durante o experimento (Tabela 1). Estes resultados estão de acordo com os sugeridos para a espécie (Saint-Paul, 1986).

Os resultados do peso médio inicial, peso médio final, ganho de peso médio, conversão alimentar aparente e taxa de crescimento específico do experimento da ração com amilase estão representados na Tabela 2. A taxa de sobrevivência foi de $100 \%$. Nesse experimento, a inclusão de amilase exógena a 0,05\% resultou em me- 
lhor desempenho zootécnico dos juvenis de tambaqui. Entretanto, não houve a mesma tendência quando os níveis de amilase na ração aumentaram.

Uma hipótese para a obtenção desse resultado seria o fato de a amilase ter disponibilizado uma quantidade excessiva de glicose, oriunda de ingredientes como o farelo de soja, fubá de milho e farinha de trigo contidos na ração, depositando glicogênio em excesso no fígado dos peixes e prejudicando assim o seu crescimento
(Hemre et al., 2002). Este fenômeno torna obrigatório o monitoramento da capacidade do fígado dos peixes em metabolizar e armazenar carboidratos (Legate et al., 2001).

Trabalhos que testam a inclusão de enzimas digestivas exógenas nas rações mostram resultados positivos no desempenho zootécnico de diferentes animais. MoraJaímes et al. (2002), usando a amilase produzida a partir de Aspergillus niger e a $\alpha$-amilase produzida a par-

Tabela 1. Média e desvio-padrão dos parâmetros físico-químicos da água dos tanques com juvenis de tambaqui, C. macropomum, submetidos à ração suplementada com enzimas exógenas ${ }^{(1)}$.

\begin{tabular}{|c|c|c|c|c|}
\hline \multirow[t]{2}{*}{ Parâmetros } & \multicolumn{4}{|c|}{ Concentração das enzimas (\%) } \\
\hline & 0,00 & 0,05 & 0,10 & 0,20 \\
\hline & \multicolumn{4}{|c|}{ Amilase } \\
\hline $\mathrm{pH}$ & $4,5 \pm 0,00 \mathrm{a}$ & $4,5 \pm 0,00 \mathrm{a}$ & $4,5 \pm 0,00 \mathrm{a}$ & $4,5 \pm 0,00 \mathrm{a}$ \\
\hline Temperatura $\left({ }^{\circ} \mathrm{C}\right)$ & $27,5 \pm 0,00 \mathrm{a}$ & $27,5 \pm 0,00 \mathrm{a}$ & $27,5 \pm 0,00 \mathrm{a}$ & $27,5 \pm 0,00 \mathrm{a}$ \\
\hline Condutividade $\left(\mu \mathrm{S} \mathrm{cm}^{-1}\right)$ & $19,5 \pm 0,05 \mathrm{a}$ & $19,4 \pm 0,24 \mathrm{a}$ & $19,5 \pm 0,05 \mathrm{a}$ & $19,5 \pm 0,00 \mathrm{a}$ \\
\hline $\mathrm{O}_{2}$ dissolvido $\left(\mathrm{mg} \mathrm{L}^{-1}\right)$ & $4,8 \pm 0,02 \mathrm{a}$ & $4,8 \pm 0,03 \mathrm{a}$ & $4,8 \pm 0,02 \mathrm{a}$ & $4,8 \pm 0,02 \mathrm{a}$ \\
\hline \multirow[t]{2}{*}{ Amônia $\left(\mathrm{mg} \mathrm{L}^{-1}\right)$} & $0,14 \pm 0,04 \mathrm{a}$ & $0,13 \pm 0,07 \mathrm{a}$ & $0,13 \pm 0,06 \mathrm{a}$ & $0,13 \pm 0,03 \mathrm{a}$ \\
\hline & \multicolumn{4}{|c|}{ Lipase } \\
\hline $\mathrm{pH}$ & $4,4 \pm 0,05 \mathrm{a}$ & $4,4 \pm 0,05 \mathrm{a}$ & $4,5 \pm 0,06 a$ & $4,5 \pm 0,06 \mathrm{a}$ \\
\hline Temperatura $\left({ }^{\circ} \mathrm{C}\right)$ & $28,2 \pm 0,05 \mathrm{a}$ & $28,2 \pm 0,00 \mathrm{a}$ & $28,2 \pm 0,05 \mathrm{a}$ & $28,2 \pm 0,06 \mathrm{a}$ \\
\hline Condutividade $\left(\mu \mathrm{S} \mathrm{cm}^{-1}\right)$ & $18,7 \pm 0,13 \mathrm{a}$ & $18,9 \pm 0,22 \mathrm{a}$ & $19,3 \pm 0,21 \mathrm{a}$ & $18,9 \pm 0,13 \mathrm{a}$ \\
\hline $\mathrm{O}_{2}$ dissolvido $\left(\mathrm{mg} \mathrm{L}^{-1}\right)$ & $5,2 \pm 0,26 \mathrm{a}$ & $4,6 \pm 0,24 \mathrm{a}$ & $4,8 \pm 0,31 \mathrm{a}$ & $4,6 \pm 0,45 \mathrm{a}$ \\
\hline \multirow[t]{2}{*}{ Amônia $\left(\mathrm{mg} \mathrm{L}^{-1}\right)$} & $0,14 \pm 0,04 \mathrm{a}$ & $0,13 \pm 0,07 \mathrm{a}$ & $0,14 \pm 0,06 \mathrm{a}$ & $0,13 \pm 0,03 \mathrm{a}$ \\
\hline & \multicolumn{4}{|c|}{ Protease } \\
\hline $\mathrm{pH}$ & $4,1 \pm 0,08 \mathrm{a}$ & $4,2 \pm 0,13 \mathrm{a}$ & $4,1 \pm 0,10 \mathrm{a}$ & $4,1 \pm 0,05 \mathrm{a}$ \\
\hline Temperatura $\left({ }^{\circ} \mathrm{C}\right)$ & $26,7 \pm 0,24 \mathrm{a}$ & $26,4 \pm 0,01 \mathrm{a}$ & $26,4 \pm 0,20 \mathrm{a}$ & $26,2 \pm 0,15 \mathrm{a}$ \\
\hline Condutividade $\left(\mu \mathrm{S} \mathrm{cm}^{-1}\right)$ & $19,8 \pm 0,48 \mathrm{a}$ & $19,5 \pm 0,22 \mathrm{a}$ & $19,7 \pm 0,13 \mathrm{a}$ & $19,6 \pm 0,49 \mathrm{a}$ \\
\hline $\mathrm{O}_{2}$ dissolvido $\left(\mathrm{mg} \mathrm{L}^{-1}\right)$ & $6,2 \pm 0,10 \mathrm{a}$ & $6,2 \pm 0,10 \mathrm{a}$ & $6,2 \pm 0,05 \mathrm{a}$ & $6,2 \pm 0,05 \mathrm{a}$ \\
\hline Amônia $\left(\mathrm{mg} \mathrm{L}^{-1}\right)$ & $0,15 \pm 0,05 \mathrm{a}$ & $0,34 \pm 0,04 \mathrm{a}$ & $0,24 \pm 0,02 \mathrm{a}$ & $0,13 \pm 0,02 \mathrm{a}$ \\
\hline
\end{tabular}

(1)Médias seguidas da mesma letra, na linha, não diferem entre si pelo teste de Tukey a 5\% de probabilidade.

Tabela 2. Média e desvio-padrão do peso inicial (PI), peso final (PF), ganho de peso (GP), conversão alimentar aparente (CAA) e taxa de crescimento específico (TCE) de juvenis de tambaqui, Colossoma macropomum, submetidos à ração suplementada com diferentes níveis de amilase, lipase e protease exógenas ${ }^{(1)}$.

\begin{tabular}{cccrcc}
\hline Amilase $(\%)$ & PI $(\mathrm{g})$ & PF $(\mathrm{g})$ & GP $(\mathrm{g})$ & \multicolumn{1}{c}{ CAA } & TCE \\
\hline 0,00 & $12,24 \pm 1,72 \mathrm{a}$ & $18,28 \pm 1,80 \mathrm{~b}$ & $6,04 \pm 1,05 \mathrm{~b}$ & $1,79 \pm 0,31 \mathrm{~b}$ & $1,45 \pm 0,31 \mathrm{~b}$ \\
0,05 & $12,06 \pm 2,39 \mathrm{a}$ & $23,67 \pm 2,89 \mathrm{a}$ & $12,50 \pm 3,41 \mathrm{a}$ & $1,25 \pm 0,56 \mathrm{a}$ & $2,41 \pm 1,09 \mathrm{a}$ \\
0,10 & $12,85 \pm 1,76 \mathrm{a}$ & $18,83 \pm 2,44 \mathrm{~b}$ & $5,98 \pm 0,89 \mathrm{~b}$ & $1,72 \pm 0,16 \mathrm{~b}$ & $1,37 \pm 0,14 \mathrm{~b}$ \\
0,20 & $12,59 \pm 1,46 \mathrm{a}$ & $19,36 \pm 2,50 \mathrm{~b}$ & $6,66 \pm 1,00 \mathrm{~b}$ & $1,60 \pm 0,20 \mathrm{~b}$ & $1,53 \pm 0,10 \mathrm{~b}$ \\
\hline Lipase $(\%)$ & & & & & \\
\hline 0,00 & $20,89 \pm 4,71 \mathrm{a}$ & $30,10 \pm 4,47 \mathrm{~b}$ & $9,21 \pm 1,22 \mathrm{c}$ & $2,53 \pm 0,32 \mathrm{c}$ & $1,34 \pm 0,34 \mathrm{c}$ \\
0,05 & $19,11 \pm 2,32 \mathrm{a}$ & $31,03 \pm 2,80 \mathrm{~b}$ & $11,91 \pm 2,23 \mathrm{~b}$ & $1,85 \pm 0,32 \mathrm{~b}$ & $1,60 \pm 0,27 \mathrm{~b}$ \\
0,10 & $18,57 \pm 3,36 \mathrm{a}$ & $29,15 \pm 3,83 \mathrm{~b}$ & $10,58 \pm 1,65 \mathrm{bc}$ & $1,86 \pm 0,52 \mathrm{bc}$ & $1,63 \pm 0,29 \mathrm{bc}$ \\
0,20 & $20,72 \pm 2,22 \mathrm{a}$ & $36,00 \pm 3,44 \mathrm{a}$ & $15,28 \pm 1,32 \mathrm{a}$ & $1,51 \pm 0,24 \mathrm{a}$ & $1,97 \pm 0,08 \mathrm{a}$ \\
\hline Protease $(\%)$ & & & & & \\
\hline 0,00 & $24,51 \pm 2,94 \mathrm{a}$ & $37,95 \pm 3,40 \mathrm{a}$ & $13,45 \pm 0,56 \mathrm{a}$ & $1,32 \pm 0,06 \mathrm{a}$ & $1,57 \pm 0,12 \mathrm{a}$ \\
0,05 & $22,31 \pm 2,21 \mathrm{a}$ & $34,64 \pm 3,73 \mathrm{a}$ & $12,32 \pm 1,88 \mathrm{a}$ & $1,31 \pm 0,26 \mathrm{a}$ & $1,55 \pm 0,17 \mathrm{a}$ \\
0,10 & $23,28 \pm 2,23 \mathrm{a}$ & $34,41 \pm 4,17 \mathrm{a}$ & $11,14 \pm 2,17 \mathrm{a}$ & $1,77 \pm 0,38 \mathrm{a}$ & $1,39 \pm 0,14 \mathrm{a}$ \\
0,20 & $24,94 \pm 2,57 \mathrm{a}$ & $37,96 \pm 1,53 \mathrm{a}$ & $13,03 \pm 2,72 \mathrm{a}$ & $1,61 \pm 0,39 \mathrm{a}$ & $1,51 \pm 0,36 \mathrm{a}$ \\
\hline
\end{tabular}

${ }^{(1)}$ Médias seguidas da mesma letra, na coluna, não diferem entre si pelo teste de Tukey a 5\% de probabilidade. 
tir de Bacillus licheniformis, como aditivos na ração, aumentaram a digestibilidade do amido do sorgo, na alimentação de cordeiros. Yin et al. (2001) testaram o efeito de um complexo enzimático formado por carboidrases e proteases na alimentação de suínos, e verificaram que houve melhora na digestibilidade da matéria seca, energia bruta e proteína bruta.

Espécies onívoras de peixes não apresentam problemas para digerir o amido por secretarem amilase em todas as porções do intestino (Hepher, 1988; Hidalgo et al., 1999; Baldisserotto, 2002). O tambaqui, como espécie de peixe onívoro, apresenta maior atividade enzimática na região dos cecos pilóricos e intestino proximal (Toniolo, 2001).

O experimento da inclusão de $0,2 \%$ de lipase exógena foi a que melhor influenciou o desempenho zootécnico dos juvenis de tambaqui (Tabela 2), e a taxa de sobrevivência também foi de 100\%. Segundo Hepher (1988), a inclusão de lipase exógena nas rações potencializa a digestão dos lipídios, disponibilizando energia de natureza não-protéica e causando o efeito poupador da proteína para fins energéticos. Esta tendência foi constatada neste trabalho.

Alguns trabalhos foram realizados testando os níveis de energia a partir de variações dos componentes lipídicos da ração, para melhorar o aproveitamento da proteína. Martino et al. (2002) testaram diferentes níveis de inclusão de lipídios (0, 4, 8 e 12\% na ração) na alimentação do surubim, Pseudoplatystoma coruscans. Os autores puderam observar que o desempenho zootécnico do peixe melhora com o incremento de lipídio na dieta.

Shiau \& Lan (1996), em trabalho realizado com a garoupa, Epinephelus malabaricus, não encontraram mudança na taxa de crescimento do peixe, ao diminuir o conteúdo de proteína na dieta e aumentar o nível energético com lipídeos. Isto sugere que, quando os requerimentos calóricos são alcançados, a proteína pode ter o seu uso otimizado. Aumentando o aproveitamento dos lipídios na dieta, as exigências protéicas dos peixes podem diminuir (Espinós et al., 2003). Neste trabalho foi observado que, mesmo com dietas isoprotéicas nos tratamentos, o crescimento dos juvenis de tambaqui revelou índices zootécnicos melhorados com a adição de lipase na ração. Esses resultados mostram que a maior disponibilidade de lipídios observada com o uso de lipase exógena influencia o desempenho do tambaqui.
Seixas Filho et al. (2000) observaram diferença na atividade específica da lipase intestinal de piau e piracanjuba, e sugerem que essas diferenças estão relacionadas ao balanceamento inadequado da ração comercial utilizada na alimentação desses peixes.

Os resultados do desempenho zootécnico dos juvenis de tambaqui alimentados com a ração suplementada com protease exógena estão representados na Tabela 2. A taxa de sobrevivência foi de $100 \%$. A inclusão de protease exógena não influenciou o desempenho zootécnico dos juvenis de tambaqui. Esta tendência foi observada também por Fischer et al. (2002), testando o efeito da inclusão de um composto multienzimático à base de proteases, amilases e celulases na dieta de frangos de corte. Os autores observaram que a inclusão do complexo multienzimático não proporcionou ganhos no desempenho dos animais.

Cavero (2004) observou que a adição de protease exógena teve influência positiva no desempenho zootécnico de juvenis de pirarucu, que exigem alta concentração de proteína na dieta, em razão do seu hábito alimentar.

Dabrowski et al. (1992) observaram que a inibição da tripsina leva à inibição da amilase. Ao testar no Salvelinus alpinus L. alimentos à base de farelo de soja, verificaram um decréscimo da atividade da amilase. Alguns trabalhos realizados, substituindo a farinha de peixe por fontes protéicas de origem vegetal, alertam sobre a presença de fatores antinutricionais (Robaina et al., 1997; Burel et al., 2000), que em geral são inibidores de proteases, limitando a porcentagem de inclusão da proteína vegetal na formulação de rações para espécies carnívoras (Boonyaratpalin et al., 1998). No caso do tambaqui, que parece possuir um bom aproveitamento da proteína de origem vegetal, a inclusão de protease não influenciou significativamente o crescimento dos peixes. Esses resultados devem estar relacionados a uma possível auto-suficiência do tambaqui para digerir a porcentagem de proteína presente na ração.

\section{Conclusões}

1. As enzimas exógenas amilase e lipase influenciam o desempenho zootécnico de juvenis de tambaqui, nos níveis de inclusão na ração de 0,05 e 0,2\%, respectivamente.

2. A adição de protease exógena não influencia o desempenho zootécnico de juvenis de tambaqui, em nenhum dos níveis de inclusão testados na ração. 


\section{Agradecimentos}

À Fundação de Amparo à Pesquisa do Estado do Amazonas (Fapeam), pelo suporte financeiro e a bolsa de PIBIC/Inpa, concedida a Érica da Silva Santiago Nunes; ao CNPq, pela bolsa de produtividade em pesquisa, concedida a Manoel Pereira-Filho e Rodrigo Roubach.

\section{Referências}

ARAÚJO-LIMA, C.R.M.; GOULDING, M. So fruitful fish: ecology, conservation, and aquaculture of the Amazon's tambaqui. New York: Columbia University Press, 1997. 157p.

BALDISSEROTTO, B. Fisiologia de peixes aplicada à piscicultura. Santa Maria: Ed. da UFSM, 2002. 92p.

BOONYARATPALIN, M.; SURANEIRANAT, P.; TUNPIBAL, T. Replacement of fish meal with various types of soybean products in diets for the Asian sea bass, Lates calcarifer. Aquaculture, v.161, p.67-78, 1998.

BUREL, C.; BOUJARD, T.; KAUSHIK, S.J.; BOEUF, G.; GEYTEN, S. van der; KUHN, E.R.; QUINSAC, A.; KROUTI, M.; RIBAILLIER, D. Potential of plant-protein sources as fish meal substitutes in diets for turbot Psetta maxima: growth, nutrient utilization and thyroid status. Aquaculture, v.188, p.363-382, 2000.

CAVERO, B.A.S. Uso de enzimas digestivas exógenas na alimentação de juvenis de Pirarucu, Arapaima gigas (Cuvier, 1829). 2004. 79p. Tese (Doutorado) - Universidade Federal do Amazonas, Manaus.

DABROWSKI, K.; KRUMSCHNABEL, G.; PAUKKU, M.; LABANOWSKI, J. Cyclic growth and activity of pancreatic enzymes in alevins of Artic charr (Salvelinus alpinus L.). Journal of Fish Biology, v.40, p.511-521, 1992.

ESPINÓS, F.J.; TOMAS, A.; PEREZ, L.M.; BALASCH, S.; JOVER, M. Growth of dentex fingerlings (Dentex dentex) fed diets containing different levels of protein and lipid. Aquaculture, v.218, p.479490, 2003.

FISCHER, G.; MAIER, J.C.; RUTZ, F.; BERMUDEZ, V.L. Performance of broilers fed corn soybean meal based diets, with or without inclusion of enzymes. Revista Brasileira de Zootecnia, v.31, p.402-410, 2002.

HEMRE, G.I.; MOMMSEN, T.P.; KROGDAHL, A. Carbohydrates in fish nutrition: effects on growth, glucose metabolism and hepatic enzymes. Aquaculture Nutrition, v.8, p.175-194, 2002.

HEPHER, B. Nutrition of pond fishes. New York: Cambridge University Press, 1988. 388p.

HIDALGO, M.C.; UREA, E.; SANZ, A. Comparative study of digestive enzymes in fish with different nutritional habits.
Proteolytic and amylase activities. Aquaculture, v.170, p.267283, 1999.

LEGATE, N.J.; BONEN, A.; MOON, T.W. Glucose tolerance and peripheral glucose utilization in rainbow trout (Oncorhynchus mykiss), American eel (Anguilla rostrata), and black bulhead catfish (Ameiurus melas). General and Comparative Endocrinology, v.122, p.48-59, 2001.

MARTINO, R.C.; CYRINO, J.E.P.; PORTZ, L.; TRUGO, L.C. Effect of dietary lipid level on nutritional performance of the surubim, Pseudoplatystoma coruscans. Aquaculture, v.209, p.209-218, 2002.

MENDES, P.P. Estatística aplicada à aqüicultura. Recife: Bagaço, 1999. 265p.

MORA-JAÍMES, G.; BÁCENA-GAMA, R.; MENDOZAMARTÍNEZ, G.D.; GONZÁLES-MUÑOZ, S.S.; HERRERAHARO, J.G. Respuesta productiva y fermentación ruminal en borregos alimentados con grano de sorgo tratado con amilasas. Agrociencia, v.36, p.31-39, 2002.

PEREIRA-FILHO, M. Alternativas para alimentação de peixes em cativeiro. In: VAL, A.L.; HONCZARYK, A. (Ed.). Criando peixe na Amazônia. Manaus: MCT: INPA, 1995. p.75-82.

ROBAINA, L.; MOYANO, F.J.; IZQUIERDO, M.S.; SOCORRO, J.; VERGARA, J.M.; MONTERO, D. Corn gluten and meat and bone meals as protein sources in diets for gilthead sea bream (Sparus aurata): nutritional and histological implications. Aquaculture, v.157, p.347-359, 1997.

SAINT-PAUL, U. Potential for aquaculture of South American freshwater fishes: a review. Aquaculture, v.54, p.205-240, 1986.

SEIXAS FILHO, J.T.; BRÁS, J.M.; GOMIDE, A.T.M.; OLIVEIRA, M.G.A.; DONZELE, J.L.; MENIN, E. Anatomia funcional e morfometria dos intestinos e dos cecos pilóricos do Teleostei (Pisces) de água doce Brycon orbignyanus (Valenciennes, 1849). Revista Brasileira de Zootecnia, v.29, p.313-324, 2000.

SHIAU, S.Y.; LAN, C.W. Optimum dietary protein level and protein to energy ratio for growth in grouper Epinephelus malabaricus. Aquaculture, v.145, p.256-266, 1996.

TAKAHASHI, N.S. Nutrição de peixes. Disponível em: <http:// www.jundiai.com.br/abrappesq/material11.htm>. Acesso em: 9 out. 2003.

TONIOLO, C.F.C. Estudo dos padrões de digestão enzimática e perfil metabólico em tambaqui, Colossoma macropomum (Cuvier, 1818), alimentados com diferentes teores de proteína e carboidratos em regime de confinamento. 2001. 115p. Tese (Doutorado) - Universidade Federal de São Carlos, São Carlos.

YIN, Y.L.; BAIDOO, S.K.; JIN, L.Z.; LIU, Y.G.; SCHULZE, H.; SIMMINS, P.H. The effect of different carbohydrase and protease supplementation on apparent (ileal and overall) digestibility of nutrients of five hulless barley varieties in young pigs. Livestock Production Science, v.71, p.109-120, 2001. 